\title{
Influence of Shift Work on Depression Disorder using Big Data
}

\author{
Hee-Kyung Kim ${ }^{1}$, Bu-Yeon Park ${ }^{2 *}$, Moon-Sung Jung ${ }^{3}$, Seol-Kyung Song ${ }^{4}$, \\ Sung-Taek $\mathrm{Kim}^{5}$ and Suk-Il Kim ${ }^{6}$ \\ ${ }^{1}$ Dept.of Public Health, Graduate School of Chonnam National University \\ $2^{*}$ Dept. of Hospital Medical Information, Seonam University, 7-111 Pyeongchon- \\ gil, Songak-myeon, Asan-si, Chungnam, Korea \\ ${ }^{3}$ Dept. of Real Estate, Seonam University, 7-111 Pyeongchon-gil, Songak-myeon, \\ Asan-si, Chungnam, Korea \\ ${ }^{4}$ Dept. of Dental Hygiene, Seonam University, 7-111 Pyeongchon-gil, Songak- \\ myeon, Asan-si, Chungnam Korea \\ ${ }^{5}$ Department of rehabilitation sports, Cheongam College, 1641 NokSaek-ro, \\ Suncheon, Jeonnam, Korea \\ ${ }^{6}$ Department of Child-care and welfare, Dongkang collage, 50 Dongmundea-ro, \\ Bukgu, Gwangju, Korea \\ 1'khk3406@nate.com,2*mr7570@hanmail.net, ${ }^{3}$ izoa318@hanmail.net, \\ 4ttunge@hanmail.net, ${ }^{5}$ kst6819@scjc.ac.kr, ${ }^{6}$ Kim5725@hanmail.net
}

\begin{abstract}
The purpose of this study was to investigate the effects of shift work of over 19 year old workers on depression and to find ways to resolve their depressive symptoms. Data from the study were analyzed using The sixth Korea National Health and Nutrition examination survey VI-2(2014). The results showed that the shift worker had 1.459 times $195 \%$ CI: 1.008-2.110) more depressed than the comparable worker. Particularly, there was a significant difference in the quality of life (OR: 2.353, 95\% CI: 1.771-3.128) and subjective health status (OR: 0.290, 95\% CI: 0.188-0.448). The quality of life and perception of subjective health status of shift workers were found to be related to depression. The quality of life of these shift workers and the policy approach to improve industrial safety are considered to be a way to improve the mental health of shift workers.
\end{abstract}

Keywords: Shift work, Depression, Occupation, National Health and Nutrition examination survey

\section{Introduction}

Currently, Korea is in a serious state of mental health problems such as suicide, anxiety, and depression, despite the improvement of medical technology and living standard, which is in serious danger due to social problems. In response to these mental health problems, countermeasures have been established in various and systematic ways at the national level. In particular, various studies have been conducted to prevent suicide in the face of the disgrace of OECD suicide rate (1). In the American Psychiatric Association, depressive disorder means a loss of interest or pleasure in depressed mood or interest that lasts almost every day for more than 2 weeks, with significant weight or appetite changes, changes in sleep, fatigue, and unrecognized suicidal thoughts. Depressive disorders are often caused by the surrounding environment regardless of their own will, so they are often ignorant or miss treatment periods. Depressive disorder is a dangerous mental health problem that can be treated at an early stage but can be suicidal if left alone. In

Received (June 19, 2017), Review Result (September 13, 2017), Accepted (September 15, 2017) 
depression-related studies, 3-5\% of people with depression are at a serious level requiring treatment, and $10-15 \%$ are known to be serious mental health problems leading to suicide (2). In 2011 , the prevalence of major depressive disorder lifetime prevalence was $4.0 \%$ in $2001,5.6 \%$ in 2006, and $6.7 \%$ in 2011 in the mental health state epidemiology survey of the Ministry of Health and Welfare. In addition, there is a significant increase in depression among mental health problems (3). Sleep is also an important factor in mental health, and people change their stance 20 to 30 times to maintain optimal sleep while sleeping 7-8 hours a day on average. This is because sleep is related to the smooth blood circulation and mental health of the human body, resulting in an unconscious shift in the brain, resulting in optimal sleep (4). Modern society has changed the working hours in order to meet various demand factors of the people through changes in industrial environment and cultural life. Therefore, workers are often required to work not only during the day when humans are awake, but also at night when they must rest physiologically and psychologically. Shifts in the number of shift workers are increasing due to changes in the industrial environment. In Europe and the United States in 2000, it is estimated that about $20 \%$ of the total worker is in shift work (5-6). According to the Korea National Statistical Office (KNSO), $18.9 \%$ of shift workers were working in shift work in 2014 (7). In particular, shift work has become more common in industries where continuity must be maintained due to the availability of free electricity. This type of shift work is being carried out in a wide range of sectors including transportation, defense and social security, publishing, video and information, agriculture, forestry and fisheries, business facility management, and business support(8). In the case of a shift worker, daily rhythm incongruity is disrupted by the daily cycle rhythm, which reduces the efficiency of work and negatively affects the interpersonal relationship in social relations. In addition, shift workers may experience insomnia, lack of sleep, and poor quality of sleep, resulting in loss of work efficiency and loss of the company (9). However, the more serious side effects are that they can lead to metabolic disorders, emotional problems, somatization disorders and psychiatric disorders on a personal level due to shift work stress (10). In previous studies, shift work was found to negatively affect workers' social activities, physical health and mental health. Previous work on domestic shift work has been actively conducted in a single occupation, including a study on the quality of sleep, stress and self-esteem of nurses (11), and the effects of firefighters and police officers on depression (12) In the case of foreign countries, research on shift work by various industries such as police and nurses was carried out (13). Studies conducted abroad have shown that there are many studies on shift work, chronic illness, quality of sleep, and health status (14-16). However, there was no study of the degree of depression among shift workers in all industries in Korea. The purpose of this study is to evaluate the health and nutrition level of the people and to calculate the statistics necessary for establishing and evaluating the health policy in the Ministry of Health and Welfare. By using statistical data of the National Health and Nutrition Survey, And to provide basic data for establishing effective working conditions to reduce the depression of workers by confirming the relationship with depression.

\section{Study Method}

\subsection{Subjective}

The data used to carry out this study were from The sixth Korea National Health and Nutrition examination survey VI-2. In order to improve the accuracy of the representative and estimation of the sample, we used stratified, clustered, and weighted (health Questionnaires, and screening weights). The estimation of the population mean $(\bar{Y})$ and variance $(\mathrm{V}(\bar{Y}))$ in the complex sample is as follows $(1.1)$. 


$$
\begin{gathered}
\bar{Y}=\frac{\sum_{h=1}^{H} \sum_{i=1}^{n_{h}} \sum_{j=1}^{m_{h i}} \omega_{h i j} \times y_{h i j}}{\sum_{h=1}^{H} \sum_{i=1}^{n_{h}} \sum_{j=1}^{m_{h i}} \omega_{h i j}} \\
\mathrm{~V}(\bar{Y})=\sum_{h=1}^{H} \frac{n_{h}\left(1-f_{h}\right)}{n_{h}-1} \sum_{i=1}^{n_{h}}\left(e_{h i .}-\overline{e_{h l . .}}\right) 2
\end{gathered}
$$

(h: layer, i: research, j: household, $\omega_{h i j}$ : weight, $y_{h i j}$ : value)

The weighting is adjusted to compensate for the difference between the difference in the number of households and the population at the time of the survey and the nonresponse error due to the absence of survey, so that the accuracy of the estimate can be improved. The weight standard mean is shown in (1.2).

$$
\begin{aligned}
& \bar{Y}=\sum_{i=1}^{n} w_{i} y_{i} / \sum_{i=1}^{n} w_{i} \\
& \left(y_{i}: \text { data, } w_{i}: \text { weight }\right)
\end{aligned}
$$

The subjects of this study were adult workers aged 19 and over in The sixth Korea National Health and Nutrition examination survey VI-2. The general characteristics, job related characteristics, and health - related characteristics of the subjects were included as independent variables. Depression score of 5 or more on mild depression was used as a dependent variable in the PHQ-9 depression test. The health-related characteristics included sleep quality, stress level, chronic diseases (hypertension, diabetes mellitus, tuberculosis, liver disease, cancer), cerebro-cardiovascular disease, EQ-5D and subjective health status that could affect depression. EQ5D is a tool developed for the measurement of health related quality of life developed by the EuroQol group. It is divided into five dimensions: exercise, self-care, daily life, pain / discomfort, and anxiety / depression. Each dimensions has 3 levels: no problems, some problems, extreme problems. In this study, A score below'0' indicated problematic and '1' was regarded as no problem according to the contents of EQ5D-3L user guide(17). The chronic diseases that were used in the analysis were examined for the current prevalence of hypertension, cancer, stroke, myocardial infarction and angina, hepatitis B, tuberculosis and diabetes.

\subsection{Measurement of Depression}

The sixth Korea National Health and Nutrition examination survey VI-2 used a depression module consisting of the self-report questionnaire, PHQ-9 (Patient Health Questionnaire), to measure the degree of depression. PHQ-9 was developed to meet DSM-IV(Diagnostic and statistical manual of mental disorder) diagnostic criteria for depressive episodes. No, not at all, from 0 to nearly every day, according to the severity of the symptoms, ranging from 5 to 9 points, 10 to 14 points, moderate to 15 to 19 points, severe to 20 points or more, Was used (18). In this study, more than 5 mild depressive disorder was used as the cut point of depression.

\subsection{Analysis Method}

The sixth Korea National Health and Nutrition examination survey VI-2 was revised to fit the purpose of the study. The relationship between these characteristics and depression was presented using the $\chi 2$ test. Multivariate logistic regression analysis was performed to determine the relationship between the presence of shift work and depression in the univariate control of variables with significant relationship to depression. Statistical analysis was performed using SPSS 21 and statistical significance was 0.05 or less. 


\section{Results}

\subsection{General Characteristics Related to Depression}

The general characteristics related to depression were presented in table 1. Among general characteristic, there were a significant difference in gender is noted in the female $(\mathrm{p}=0.00)$, age is noted in the 66 above $(\mathrm{p}=0.00)$, education level is noted in the elementary $(\mathrm{p}=0.00)$, household income is noted in the low $(\mathrm{p}=0.00)$, medical care $(\mathrm{p}=0.00)$ and private insurance $(\mathrm{p}=0.00)$.

Table 1. General Characteristics Related to Depression

\begin{tabular}{|c|c|c|c|c|}
\hline \multirow{2}{*}{ Characteristics } & \multirow{2}{*}{ Category } & \multicolumn{2}{|c|}{ Depression (n, weighted\%) } & \multirow{2}{*}{ p-value } \\
\hline & & No & Yes & \\
\hline \multirow[t]{2}{*}{ Gender } & male & $858(73.0)$ & $327(27.0)$ & \\
\hline & female & $1253(61.3)$ & $776(38.7)$ & 0.000 \\
\hline \multirow[t]{4}{*}{ Age(year) } & $19-35$ & $494(62.8)$ & $304(37.2)$ & \\
\hline & $36-50$ & $15(72.1)$ & $242(27.9)$ & \\
\hline & $51-65$ & $616(70.6)$ & $268(29.4)$ & \\
\hline & $\geq 66$ & $386(55.3)$ & $289(44.7)$ & 0.000 \\
\hline \multirow[t]{4}{*}{ Education } & elementary & $393(52.3)$ & $344(47.7)$ & \\
\hline & middle & $242(69.2)$ & $110(30.8)$ & \\
\hline & high & $725(67.2)$ & $343(32.8)$ & \\
\hline & collage and above & $749(71.1)$ & $305(28.9)$ & 0.000 \\
\hline \multirow[t]{4}{*}{ Household Income } & low & $325(51.9)$ & $309(48.1)$ & \\
\hline & middle low & $514(62.3)$ & $283(37.7)$ & \\
\hline & middle high & $641(71.9)$ & $261(28.1)$ & \\
\hline & high & $629(72.4)$ & $242(27.6)$ & 0.000 \\
\hline \multirow{2}{*}{$\begin{array}{l}\text { Marital } \\
\text { status }\end{array}$} & married & $1773(67.5)$ & $887(32.5)$ & \\
\hline & single & $338(63.5)$ & $216(36.5)$ & 0.107 \\
\hline \multirow[t]{2}{*}{ Residential area } & town & $1728(66.5)$ & $896(33.5)$ & \\
\hline & rural & $383(67.0)$ & $207(33.0)$ & 0.786 \\
\hline \multirow[t]{2}{*}{ Medical insurance } & Health insurance & $2054(68.2)$ & $992(31.8)$ & \\
\hline & medical care & $37(30.0)$ & $87(70.0)$ & 0.000 \\
\hline \multirow{2}{*}{$\begin{array}{l}\text { Private } \\
\text { insurance }\end{array}$} & Yes & $1646(69.2)$ & $740(30.8)$ & \\
\hline & No & $447(57.0)$ & $350(43.0)$ & 0.000 \\
\hline
\end{tabular}

\subsection{Occupation Characteristics Related to Depression}

The occupation characteristics related to depression were presented in Table 2. Among occupation characteristics, there were a significant difference in Employment type is noted in the other $(\mathrm{p}=0.005)$, Regular working is noted in the Temporary $(\mathrm{p}=0.002)$, Occupation group is noted in the Service $(\mathrm{p}=0.041)$, Form of working hours is noted in the Other( $\mathrm{p}=0.026)$ and Shift work $(\mathrm{p}=0.007)$.

\subsection{Health Characteristics Related To Depression}

The health characteristics related to depression were presented in Table 3. Among health characteristics, there were a significant difference in chronic disease $(p=0.012)$, cerebro-cardiac disease $(p=0.002)$, stress status is notes in the often $(p=0.000)$, BMI is noted in the obesity $(\mathrm{p}=0.003)$, sleep time is noted in the less than or equal to 4hours 
( $\mathrm{p}=0.000)$, quality of life is noted in the problem $(\mathrm{p}=0.000)$, subjective health state is noted in the poor $(\mathrm{p}=0.000)$

\subsection{Multiple Logistic Regression Analysis between General, Occupation, Health Characteristic and Depression}

The logistic regression analysis was conducted to examine the effect of shift work on depression in the univariate control of variables affecting depression (Table 4). General characteristic and depression were significantly male has low than female 0.733times (95\%CI: 0.556-0.966). There was no significant difference in other variables. Job characteristic were no significant difference in depression.

Table 2. Occupation Characteristics Related To Depression

\begin{tabular}{|c|c|c|c|c|}
\hline \multirow{2}{*}{ Characteristics } & \multirow{2}{*}{ Category } & \multicolumn{2}{|c|}{ Depression (n, weighted $\%)$} & \multirow{2}{*}{ p-value } \\
\hline & & No & Yes & \\
\hline \multirow[t]{3}{*}{ Employment type } & Non-precarious & $354(73.5)$ & $133(26.5)$ & \\
\hline & precarious & $504(66.3)$ & $233(33.7)$ & \\
\hline & Other* & $1249(64.4)$ & $737(35.6)$ & 0.005 \\
\hline \multirow[t]{4}{*}{ Regular working } & Regular & $585(72.4)$ & $220(27.6)$ & \\
\hline & Temporary & $200(61.5)$ & $108(38.5)$ & \\
\hline & Daily & $74(68.6)$ & $38(31.4)$ & \\
\hline & Other* & $1249(64.4)$ & $737(35.6)$ & 0.002 \\
\hline \multirow{2}{*}{$\begin{array}{l}\text { Working hours } \\
\text { week }\end{array}$} & $\mathrm{eer} \leq 40$ & $755(68.4)$ & $351(31.6)$ & \\
\hline & $\geq 41$ & $733(71.2)$ & $299(28.8)$ & 0.270 \\
\hline \multirow{3}{*}{ Occupation group } & Office & $544(73.4)$ & $198(26.6)$ & \\
\hline & Service & $284(66.1)$ & $140(33.9)$ & \\
\hline & Labor & $487(69.7)$ & $216(30.3)$ & 0.041 \\
\hline \multirow[t]{3}{*}{ Form of working hours } & rs Full time & $670(70.4)$ & $276(29.6)$ & \\
\hline & Part time & $189(65.1)$ & $90(34.9)$ & \\
\hline & Other* & $1249(64.4)$ & $737(35.6)$ & 0.026 \\
\hline \multirow[t]{3}{*}{ Employment status } & Paid worker & $859(69.3)$ & $366(30.7)$ & \\
\hline & self-employer & $368(73.6)$ & $149(26.4)$ & \\
\hline & Unpaid family worker & $88(69.9)$ & $39(30.1)$ & 0.261 \\
\hline \multirow[t]{2}{*}{ Shift worker } & No & $1233(80.8)$ & $503(28.6)$ & \\
\hline & Yes & $255(63.7)$ & $147(36.3)$ & 0.007 \\
\hline
\end{tabular}

Other* : self-employment and unpaid family

Health characteristics and depression were found to be related to stress level, quality of life, and subjective health status. The stress group was 0.255 times lower than the sometime group (95\% CI: 0.193-0.336). Quality of life was 2.353 times higher in the problem group than in the non-problem group (95\% CI: 01.771-3.128). In subjective health status, depression level was 0.597times lower in the fair group than in the poor group (95\% CI: $0.431-0.826$ ) and 0.290times lower in the good group(95\% CI: 0.188 0448). Depression was found to be 1.459 times higher in the shift work group than in the non-shift work group (95\% CI: 1.008-2.110). A significant variables were controlled and analysis. 
Table 3. Health Characteristics Related to Depression

\begin{tabular}{|c|c|c|c|c|}
\hline \multirow[t]{2}{*}{ Characteristics } & \multirow[t]{2}{*}{ Category } & \multicolumn{2}{|c|}{$\begin{array}{l}\text { Depression(n, } \\
\text { weighted } \%)\end{array}$} & \multirow[t]{2}{*}{ p-value } \\
\hline & & No & Yes & \\
\hline \multirow[t]{2}{*}{ Chronic disease } & None & $1626(67.6)$ & $777(32.4)$ & \\
\hline & Yes & $485(61.8)$ & $326(38.2)$ & 0.012 \\
\hline \multirow{2}{*}{$\begin{array}{l}\text { Cerebrovascular } \\
\text { disease }\end{array}$} & None & $2049(66.9$ & 1043(33.1) & \\
\hline & Yes & 62( $\begin{array}{r}\text { (0.9) } \\
\text { (1) }\end{array}$ & 60(49.1) & 0.001 \\
\hline \multirow[t]{2}{*}{ Stress state } & Sometimes & $1640(77.4$ & $501(22.6)$ & \\
\hline & Often & 444(44.9) & $584(55.1)$ & 0.000 \\
\hline \multirow[t]{4}{*}{ BMI* } & Underweight & $79(52.6)$ & $86(47.4)$ & \\
\hline & Normal weight & $1403(67.5$ & $702(32.5)$ & \\
\hline & Obesity & ) & $616(67.5)$ & \\
\hline & & $616(67.5)$ & & 0.003 \\
\hline \multirow[t]{4}{*}{ Sleep time } & $4 \geq$ & $74(35.0)$ & $123(65.0)$ & \\
\hline & $5-8$ & $1883(69.3$ & $862(30.7)$ & \\
\hline & $\geq 9$ & ) & $99(46.1)$ & \\
\hline & & $126(53.9)$ & & 0.000 \\
\hline \multirow[t]{3}{*}{ Quality of life(EQ-5D) } & No problem & $645(48.7)$ & $659(51.3)$ & \\
\hline & Problem & $1466(76.8$ & $442(23.2)$ & \\
\hline & & ) & & 0.000 \\
\hline \multirow{4}{*}{ Subjective health state } & Good & $592(82.1)$ & 138(17.9) & \\
\hline & Fair & $1189(68.2$ & $537(31.8)$ & \\
\hline & Poor & ) & $428(56.5)$ & \\
\hline & & $330(43.5)$ & & 0.000 \\
\hline \multirow[t]{3}{*}{ Smoking } & None & $783(67.7)$ & $391(32.3)$ & \\
\hline & Current smoker & $1300(65.7$ & $694(34.3)$ & \\
\hline & & ) & & 0.302 \\
\hline \multirow[t]{3}{*}{ Drink } & None & $973(65.1)$ & $545(34.9)$ & \\
\hline & over one glass per month & $1112(66.5$ & $544(32.6)$ & \\
\hline & & ) & & 0.269 \\
\hline
\end{tabular}

BMI* : Body mass index

\section{Discussion}

This study was conducted to investigate General, Job and Health characteristics that affect depression in 19 - year - old shift workers and to find ways to improve their work efficiency by solving their depression. The results showed that depression was more common in women than in men. This is consistent with the results of Lee's study(1), which examined factors related to workers' depression. In the case of women, the roles of women in the home and their role in society seem to be higher in women's depression in social practices that are not easy to understand in the same position as men. In addition, according to the statistics of women's families in 2012, the findings that women feel discriminated against men in gender are disproving the fact that women are not treated equally with men in society. Job related traits and depression were not related. In this paper Lee(1), which studies the relationship between work environment and depression, the working environment, especially the clean and pleasant environment, was associated with depressive symptoms. In a study by Park (2) who studied depression in Korean adult 
men and women, there was a significant difference in depression between day laborers. In this study, it was not related to depression because only the relation between occupation and job characteristics was analyzed rather than the workplace environment. However, in a study by Kim (19) that investigated the relationship between depression and firefighting officers, depression was high in a group with a high workforce such as firefighting. This is consistent with the high depression in the unemployed group in this study. The more dangerous and tough the task is, the higher the depression will be. In the health characteristics, the level of stress, quality of life, and subjective health status were significantly different from depression. The higher the level of stress experience, the higher the depression. At the stress level, the number of occasional feelings was lower than that of the frequent feelings. This is consistent with the results of Kim's (20) study on fire-fighters that job stress negatively affects fatigue and depression. Stress reduces the efficiency of work and eventually causes social costs such as industrial accidents. The quality of life was 2.353 times higher in the group with problems than the group without problems. This is consistent with Kim's (21) study of workers' shift work experience. Workers who are in shift work are separated from interpersonal relationships and feel isolated and uneasy. In addition, the quality of life is inevitably lowered by experiencing physical anxiety such as health concerns and getting away from regular life style. The higher the subjective health status, the lower the depression level. This is in agreement with the findings of Kim (22) who studied married middle age. Most workers who think that their subjective health status is good are considered to be regular workers or high quality workers. However, since shift workers are not regular working patterns, there are many workers who are hard to exercise regularly. Therefore, it seems that there is an inverse correlation between subjective health status and depression. The shift worker showed 1.459 times higher depression level than the comparison worker. This study was conducted by Park (23) who studied the relationship between shift work and depression, Kim(11) who studied nurses, $\mathrm{Bae}(12)$ investigated the relationship between police officers' of depression, And Elisabeth Flo (15) on the health problems of nurse shift workers. The results of Costa's study (24) suggest that shift workers who have not had constant working hours show mental changes as well as physical changes as well as differences in lifestyle, group personality, family relationship, and social status. Most of these mental changes have negative consequences and cannot be reversed.

Table 4. Multiple Logistic Regression Analysis between General Occupation, Health Characteristic and Depression

\begin{tabular}{llrrr}
\hline \multirow{2}{*}{ Independent variables } & & Odds & \multicolumn{2}{c}{$95 \% \mathrm{CI}^{*}$} \\
\cline { 3 - 5 } & & ratio & Lowest & highest \\
\hline Gender(female) & male & 0.733 & 0.556 & 0.966 \\
\hline Age(66 and over) & $19-35$ & 1.590 & 0.866 & 2.920 \\
& $36-50$ & 1.166 & 0.646 & 2.105 \\
& $51-65$ & 0.995 & 0.598 & 1.656 \\
\hline Education & elementary and below & 1.016 & 0.567 & 1.822 \\
(collage and above) & middle & 0.849 & 0.495 & 1.457 \\
& high & 1.156 & 0.783 & 1.705 \\
House Income(high) & low & 1.643 & 0.847 & 3.187 \\
& middle low & 1.372 & 0.939 & 2.006 \\
& middle high & 0.958 & 0.694 & 1.322 \\
\hline Medical insurance & Health insurance & 0.645 & 0.251 & 1.654 \\
(medical care) & & & & \\
Private insurance(no) & Yes & 0.976 & 0.627 & 1.517
\end{tabular}




\begin{tabular}{lllll}
\hline Employment type(other*) & Non-precarious & 0.775 & 0.390 & 1.540 \\
& precarious & 0.800 & 0.451 & 1.419 \\
\hline Regular working(other*) & Regular & 1.188 & 0.691 & 2.042 \\
& Temporary & 1.241 & 0.711 & 2.165 \\
& Daily & 1.000 & $\cdot$ &. \\
\hline Occupation group(labor) & Office & 0.651 & 0.450 & 0.942 \\
& Service & 0.826 & 0.580 & 1.177 \\
\hline Form of working hours & Full time & 1.151 & 0.730 & 1.817 \\
(part time) & & & & \\
\hline Chronic disease(yes) & None & 1.043 & 0.694 & 1.567 \\
\hline Cerebro-cardiovascular & None & 1.189 & 0.569 & 2.483 \\
disease(yes) & & & & \\
\hline Stress state(often) & Sometimes & 0.255 & 0.193 & 0.336 \\
\hline Body mass index(obesity) & Underweight & 2.214 & 1.143 & 4.289 \\
& Normal weight & 1.243 & 0.911 & 1.697 \\
\hline Sleeping time(9 and over) & $4 \geq$ & 2.107 & 0.850 & 5.222 \\
& $5-8$ & 0.659 & 0.367 & 1.15 \\
\hline Quality of life(problem) & No problem & 2.353 & 1.771 & 3.128 \\
\hline Subjective health state & Good & 0.290 & 0.188 & 0.448 \\
(poor) & Fair & 0.597 & 0.431 & 0.826 \\
\hline Shift worker(no) & Yes & 1.459 & 1.008 & 2.110 \\
\hline
\end{tabular}

Other*:self-employment and unpaid family

$\mathrm{CI}^{*}:$ confidence interval

\section{Conclusion}

This study was analyzed using The sixth Korea National Health and Nutrition examination survey VI-2. The National Health and Nutrition Survey data, which consist of nationwide survey sites, can ensure accuracy and reliability. The results showed that the shift worker had 1.459 times more depression than the non-shift worker. In particular, there was a significant difference in quality of life (OR: 2.353) and subjective health status (OR: 0.290). Quality of life and perception of health status were found to be related to depression. The quality of life of these shift workers and the policy approach to improve industrial safety are considered to be a way to improve the mental health of shift workers. In this study, The sixth Korea National Health and Nutrition examination survey VI-2 were used, so the environment and working experience of the industry director were not considered. This empirical study is expected to be conducted in the future.

\section{Acknowledgments}

This paper is received and expanded version of a paper entitled[The relationship of shift worker and depression using big data] presented at[6th International Conference on Next Generation Computer and Information Technology (NGCIT 2017), Ho Chi Minh City, Vietnam last August 16-18, 2017]

\section{References}

[1] H. Lee, M. Sohn and M. Choi, "Factors Associated with Depression among Workers by Socio-economic Factors, Health Behaviors, and Characteristics of Work Environment”, Korean J Health Educ Promot, vol.30, no.5, (2013), pp.125-138.

[2] C. Park and J. Lee, "Analysis of Factors Affecting the Change of Depression of Korean Adult Male and Female”, Healthy and medical society, vol. 29, (2011), pp.99-128. 
[3] M. Cho, J. Park, A. Bae, J. Bae, J. Son, J. An, D. Lee, Y. Lee, J. Lee, S. Jang, I. Jung, S. Cho and J. Hong, "The Epidemiological Survey of Mental Disorders in Korea 2011", Seoul, Seoul National University, (2011).

[4] H. Kim, "Rem optimal for a healthy sleeper weather Alarm pillow Development", Journal of the Korea Institute of Electronic Communication Sciences, vol.11, no.2, (2016), pp.223-228.

[5] X-S. Wang, M.E.G. Amstrong, B.J Cairns, T.J. Key and R.C. Travis, "Shift work and chronic disease: the epidemiological evidence”, Occup Med (Lond), vol.61, no.2, (2011), pp.78-89.

[6] C. A. Crispima, J. Waterhousec, A. R. Dâmasoa, I. Z. Zimberga, H. G. Padilhaa, L. M. Oyamaa, S. Tufika and M. T. de Melloa, "Hormonal appetite control is altered by shift work: a preliminary study", Metabolism, vol.60, no.12, (2011), pp.1726-1735.

[7] Statistics Korea, http://kostat.go.kr/portal/korea/index.action.

[8] Y. Jeong, E. Lee and Y Won, "Concept Analysis of Shift Work Maladaptation Syndrome", J Muscle Jt Health, vol.21, no.2, (2014), pp.135-144.

[9] H. Kim, I. Kim and G. Seo, "sleep medicine and psychophysiology", vol.5, no.1, (1998), pp.71-79.

[10] J. Woo and T.T. Postolache, "The impact of work environment on mood disorders and suicide: Evidence and implications", Int J Disabil Hum Dev, vol.7, no.2, (2008), pp.185-200.

[11] B. Kim, M. Choi, T. Kim, H. Kim and H. Eun, "Psychosomatic Symptoms of Rotating Shift and Daytime Working Nurses in a General Hospital”, Korean J Psychosom Med, vol.22, no.2, (2014), pp.7986.

[12] S. Bae, Y. Lee, S. Kim, I. Cho, J. Kim, S. Koh and S. Cho, "Rotating Shift and Daytime Fixed Work Schedules as a Risk Factor for Depression in Korean Sleep patterns, Daytime sleepiness and personality factors in rotating shift workers Police Officers", Sleep Medicine and Psychophysiology, vol. 17, no. 1, (2010), pp. 28-33.

[13] Fido A, Ghali A, "Detrimental Effects of Variable Work Shifts on Quality of Sleep, General Health and Work Performance", Med Princ Pract, vol. 17, no.6, (2008), pp.453-457.

[14] A. Pan, E. S. Schernhammer, Q. Sun and F. B. Hu, "Rotating night shift work and risk of type 2 diabetes: two prospective cohort studies in women", PLoS Med, vol.8, no.12, (2011), pp.1-8.

[15] E. Flo, S. Pallesen and N. Mageroy "Shift work disorder in nurses - assessment, prevalence and related health problems", PLoS One, vol. 7, no.4, (2012), pp.1-9

[16] G. Costa. "Shift work and health: current problems and preventive actions", Safety and Health Work, vol. 1, no.2, (2010), pp.112-123

[17] EuroQol Research Foundation, "EQ-5D-3L User Guide Basic information on how to use the EQ-5D-3L instrument", Rotterdam Netherlands, (2015).

[18] J. An, M. Eun, R. Seo, K. Lim, J. Shin and J. Kim, "Standardization of the Korean version of Screening Tool for Depression(Patient Health Questionnaire-9, PHQ-9)", J Korean Soc Biol Ther Psychiatry, vol 19, no 1, (2013), pp.142-150.

[19] T. Kim, K. Kim and Y. Ahn, "Relationship between Job Stress and Depressive Symptoms among Field Fire-fighters", Korean J Occup Environ Med, vol. 22, no. 4, (2010), pp.378-387.

[20] K. Kim, J. Park, B. Park, S. Kim and Y. Hwang, "The Effects of Job Stress with Depression and Fatigue of Firemen", International J. of contents, vol. 14, no.3, (2014), pp.223-231.

[21] Y. Kim, Y. Kim, M. Koo, S. Kim, N. Lee and K. Jang, "Workers' Experiences in Shift Work", Journal of Korean Academy of Community Health Nursing, vol.18, no.2, (2007), pp.284-292.

[22] H. Kim and S. Kim, "A Converged Study about Influences of Job Stress, Job Security, Depression, Family Bond, Subjective Health Status, Social Support on Quality of Life in Married Middle-Aged Male", Journal of the Korea Convergence Society, vol. 8. no. 3, (2017), pp.101-114.

[23] J. Park, S. Sun and M. Noh, "The Relationship between Shift Work and Depressive Symptom”, Korean J Fam Pract, vol. 6, no.2, (2016), pp.63-69

[24] G.Costa, "Shift work and occupational medicine: an overview", Occupational Medicine, vol.53, no.2, (2003), pp.83-88.

[25] http://www.cqaimh.org/index.html, PHQ9-overview.

\section{Authors}

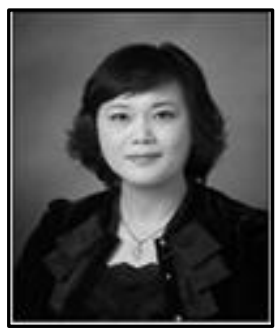

Hee-Kyeong Kim, she received she is MS degrees in Nursing from Chodang University, Korea in 2008. She completed Graduate School of Chonnam National University Korea in 2015. She research interests Nursing education, Health Promotion and Medical Administration 

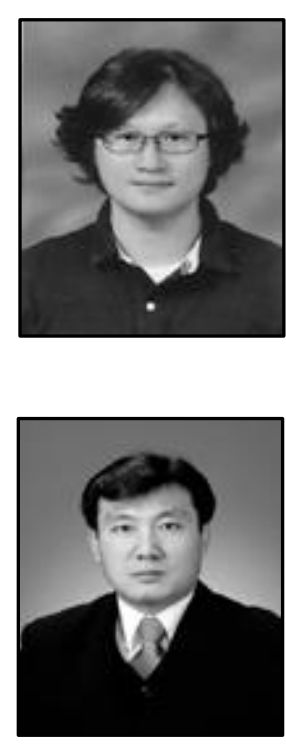

Moon-Sung Jung, he received his LL.B., and LL.M., LL.D. degrees in Law in 1989, 1992, and 2003, respectively, from the Honam, Jeonju University, Korea. He joined Seonam University, where he is currently as associate professor in the department of Security Service and Private investigation. His research interest Intellectual Property Rights, Regulations of Food Hygienic, Health \& Medical Administration.

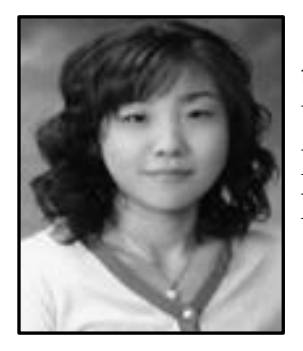

Seol-Kyung Song, she received she is MS degrees in Health from the Wonkwang University, Korea in 2004. She joined Seonam University, where she is currently as professor in the department of Dental Hygiene. She research interests Dental Health and Health Education

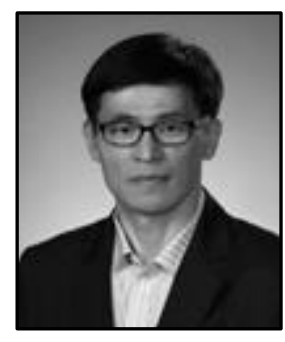

Seong-Teak Kim, he received his $\mathrm{PhD}$ degrees in Science from Chosun University, Korea in 2005. He joined Cheongam College, Where he is currently as associate professor in the department of rehabilitation sports. He is research interests include sports and leisure activities.

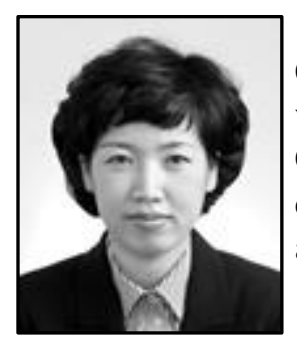

Suk-Il Kim, she received is $\mathrm{PhD}$ degrees in Journalism from Chngang University, Korea in 2015. She joined Dongkang College, where she is currently as associate professor in the department of Child and welfare. She is research interests include Child development, health and safety management, program development and evaluation of infant child. 